\title{
The relationship between clinical placement duration and students' satisfaction with the quality of supervision and learning environment: A mediation analysis
}

\author{
Alberto González-García ${ }^{1}$ \\ Vicente Martínez-Vizcaíno ${ }^{4,5}$ \\ Ana Díez-Fernández ${ }^{2} \odot \mid$ Helena Leino-Kilpi ${ }^{3}$ \\ Camilla Strandell-Laine ${ }^{6}$ \\ ${ }^{1}$ Universidad de Granada. Facultad de Ciencias de la Salud, Grupo de Investigación en Estudios Sociosanitarios (CESS), Granada, Spain \\ ${ }^{2}$ Universidad de Castilla-La Mancha, Facultad de Enfermería de Cuenca, Grupo de Investigación en Estudios Sociosanitarios (CESS), Cuenca, Spain \\ ${ }^{3}$ Department of Nursing Science, University of Turku, Turku University Hospital, Turku, Finland \\ ${ }^{4}$ Universidad de Castilla-La Mancha, Facultad de Enfermería de Cuenca, Grupo de Investigación en Estudios Sociosanitarios (CESS)., Cuenca, Spain \\ ${ }^{5}$ Facultad de Ciencias de la Salud. Universidad Autónoma de Chile, Talca, Chile \\ ${ }^{6}$ Novia University of Applied Sciences, Turku, Finland
}

\section{Correspondence}

Ana Díez-Fernández, Centro de Estudios Sociosanitarios, Universidad de Castilla-La Mancha, Calle Santa Teresa de Jornet S/N, Cuenca 16071, Spain.

Email: ana.diez@uclm.es

\section{Funding information}

European Regional Development Fund (ERDF)/Fondo Europeo de Desarrollo Regional (FEDER), Grant/Award Number: DOCM 19/02/2020; Grant for Stays in Other Universities and Research Centers co-financed by the European Regional Development 2014-2020, Grant/Award Number: 2014ES16RFOP010; Nurse Education Foundations (Sairaanhoitajien koulutussäätiö) fund

\begin{abstract}
Multiple factors that influence the learning experience of nursing students while they are in clinical training have been identified, such as the clinical learning environment, the supervision provided by supervisors, and the level of cooperation with the nurse teacher. The objective was to examine whether the relationship between the clinical placement duration and overall satisfaction with clinical training is mediated by the supervisory relationship and learning environment. A secondary analysis was conducted using the data from a cross-sectional study conducted in 17 higher educational institutions in nine European countries with the Clinical Learning Environment, Supervision and Nurse Teacher scale $(n=1903$ pre-registration nursing students). Satisfaction with the supervisor and a good learning environment mediated the relationship between clinical placement duration and overall satisfaction as perceived by the students. Nursing students with longer clinical placement durations were more satisfied with clinical training as a result of both their satisfaction with their supervisor and their perceptions of good learning environment. The optimal duration a nursing student should remain in the different practice settings is approximately 7 weeks.
\end{abstract}

KEYWORDS

clinical learning environment, clinical placement, clinical training, mediation analysis, nursing education, supervisory nursing

\section{Key points}

- Students with longer placement duration were more satisfied with their supervisors. 
- Students in long-duration clinical training perceived a better learning environment.

- The optimal duration for remaining in the practice settings should be approximately 7 weeks.

\section{1 | INTRODUCTION}

In accordance with European directives (European Commission, 2005 2013), clinical training of the 90 European Credit Transfer System (ECTS) are defined as mandatory in pre-registration nursing education programs. Despite the harmonization of educational systems promoted by the Bologna Treaty Process (Education Audiovisual and Culture Executive Agency [EAECEA P9 Eurydice], 2009), the European Higher Education Area (EHEA) is still characterized by different structures and standards upon degree completion (Kajander-Unkuri et al., 2013; Lahtinen et al., 2014). The need for nursing students to achieve sufficient high-level competence to provide effective and high-quality nursing care has recently been highlighted (European Commission, 2020). Only when the knowledge, skills, attitudes, and values acquired during the theoretical period are applied to clinical nursing performance is the acquisition of competencies considered completed (Flinkman et al., 2017). Therefore, it is imperative to improve quality of clinical environments and the competence of clinical supervisors in the mentoring of nursing students (Jack et al., 2018; Pitkänen et al., 2018). Evaluation of the quality of supervision in practical training is therefore essential.

Learning in the practice setting is essential to prepare nursing students for the challenges of professional practice (Pitkänen et al., 2018). Supporting students' learning in the clinical setting has been a key matter of debate for a long time (Lauder et al., 2008). A good learning environment not only increases students' satisfaction but also is positively related to higher competence in European countries (Kajander-Unkuri et al., 2020). Previous studies have focused on students' perspectives on learning in clinical environments in both European contexts (Fernández-García et al., 2021; Saukkoriipi et al., 2020) and non-European contexts (Baraz et al., 2015), as well as supervisors' perspectives on students' learning in a clinical education ward (Manninen et al., 2015). Nevertheless, to our knowledge, there is no evidence on the optimum time a nursing student should remain in the different practice settings to achieve the required competencies or how this duration of the placement may be influenced by other variables.

\section{2 | BACKGROUND}

To date, multiple factors that influence the learning experience of nursing students while they are in clinical training have been identified, such as the clinical learning environment, the supervision provided by supervisors, and the level of cooperation with the nurse teacher (Papastavrou et al., 2016; Rodríguez-García et al., 2021). The term "nurse teacher" refers to the qualified nurse employed by an educational institution who is responsible for facilitating both theoretical input and skill acquisition in clinical practice (Saarikoski et al., 2009). Supervisors are experienced nurses who act as clinical mentors to nursing students in clinical settings but who are not qualified teachers (Saarikoski et al., 2013).

On the one hand, the student-supervisor relationship is essential for students' learning in the clinical environment (Lee \& Chiang, 2021), since it has been shown that this relationship impacts students' satisfaction with the clinical learning environment (Pitkänen et al., 2018; Warne et al., 2010). On the other hand, it has been established that the more students interact with the nurse teacher, the more satisfied they are with their clinical training (Saukkoriipi et al., 2020). Nonetheless, the number of meetings between students and nurse teachers has diminished dramatically since 1999, at least in the Finnish context (Saarikoski et al., 2009). Additionally, the ability of nurse teachers to apply theory to practice and to promote the use of evidence in various clinical situations remains a matter of debate (Fisher, 2005; Lambert \& Glacken, 2005; Milner et al., 2005).

Environmental factors have also been found to enhance students' clinical learning. Therefore, employee work engagement contributes to enhancing students' clinical learning experience in the practicum ward (Tomietto et al., 2016). Qualitative approaches have also shown that the insufficient qualification of nurse teachers and the lack of a supportive learning environment are among the most important factors influencing students' clinical learning (Baraz et al., 2015). Peer learning appears to enhance the student experience in clinical training and can help maximize opportunities for learning and support (Morphet et al., 2014).

However, the extent to which the duration of placement influences students' overall satisfaction with their clinical training has rarely been investigated. More specifically, to our knowledge, in no case has any attempt been made to quantify the weight of both supervision and the learning environment in students' satisfaction, nor has the relationship between these elements and the clinical placement duration been analyzed. Therefore, a mediation analysis of existing data is proposed.

It is already known that students' overall satisfaction is independent of whether they attend a polytechnic or university college (Saarikoski et al., 2013), and longer placements are esteemed better by students than shorter placements because they allow the whole nursing process to be seen (Warne et al., 2010). In this study, the term "polytechnic" is used to describe higher professional colleges that tend not to have a tradition of being research led, in contrast with university colleges. Previous studies have reported that the mean clinical placement duration in the same ward is 6 weeks (Tomietto et al., 2016), ranging during the final clinical training before graduation from 2 weeks in the Czech Republic to 18 weeks in Portugal (VisiersJiménez et al., 2021). Therefore, there is no consensus on what the optimum duration of a clinical placement is with respect to promoting students' clinical learning or what the extent of the influence of placement duration on students' overall satisfaction with their clinical training is. 


\section{3 | METHODS}

\subsection{Aim}

The aim of this study was to examine whether the relationship between the clinical placement duration and overall satisfaction with clinical training measured with the Clinical Learning Environment, Supervision and Nurse Teacher scale (CLES $+T$ ) is mediated by different factors, such as the supervisory relationship or learning environment, constituting the two sub-scales of the CLES+T: clinical learning environment and supervisory relationships.

\section{2 | Design}

This was a secondary analysis of data collected during the academic years 2007 and 2008 in a study conducted in nine European countries to provide a composite and comparative view of factors enhancing the clinical learning experiences of nursing students. The sample is described elsewhere (Warne et al., 2010). Briefly, the data were collected from 17 higher educational institutions (HEls) located in Belgium, Cyprus, England, Finland, Ireland, Italy, The Netherlands, Spain, and Sweden ( $n=1903)$. The 17 nursing schools participating in the study were a representative sample of the main approaches to pre-registration nurse education currently in use (higher professional colleges, also known as polytechnics, or university colleges). The study participants were pre-registration nursing students who undertook their clinical training in hospital settings.

The secondary analysis uses pre-existing data to explore new or additional research questions (Jacobson et al., 1993). Secondary analysis, specifically, carries its own set of methodological issues that must be addressed. These issues can be summarized as follows: Is there an appropriate fit between the primary data and secondary research questions? Is the analytic technique in the secondary analysis sufficiently similar to the analytic technique used in the primary study? Secondary analysis is appropriate when the analysis provides a similar but more focused analysis than the primary study (Heaton, 2004).

\section{3 | Data collection}

The CLES+T scale (Saarikoski et al., 2008) is an internationally widely used instrument that has been validated as a measure of students perceptions and experiences of their clinical practicum. The questionnaire focuses on the student, their hospital, and ward type and the nature of their contact with the nurse teacher. The scale consists of 34 items structured in five sub-dimensions: (a) the pedagogical atmosphere on the ward, (b) the supervisory relationships, (c) the leadership style of ward managers, (d) the premises of care on the ward, and (e) the role of the nurse teacher. The response options follow a 5-point Likert scale: (1) fully disagree, (2) disagree to some extent, (3) neither agree nor disagree, (4) agree to some extent, and (5) fully agree. This instrument has been validated in a wide range of languages, even beyond the Western European context (Al-Anazi et al., 2019; Atay et al., 2018). Therefore, it has become a reference tool in the academic nursing field.

\subsection{Ethical considerations}

The principles of research ethics and good scientific practice were followed throughout the original research process (All European Academies -ALLEA, 2017). Seventeen boards of governors were the independent guarantors of the administrative and ethical approval for the cross-sectional study. The Department of Nursing, University of Turku/Turun Yliopisto (Finland), reviewed all the ethics approvals. Within the Finnish nurse education system, ethical approval to undertake a research study (from the local ethics board) is required only where the study involves patients or relatives. This was not the case with this study.

With regard to the secondary analysis, all the authors of the primary study gave their consent to reanalyze the data and carry out this secondary analysis. In addition, permission to use the CLES+T scale was received from the principal investigator of the study and copyright holder. All of these authors are named in the acknowledgements section.

Written informed consent was required by email at the end of the students' clinical placement prior to the primary study. The right to refuse participation or to decline to answer the questions posed without any penalty or consequence was guaranteed in the informed consent. During the data collection phase, the software used did not identify individual respondents to protect their answers. The respondents answered the questionnaire by email.

\section{5 | Statistical analysis}

Both inferential statistics (Kolmogorov-Smirnov test) and graphical methods (normal probability plots) were used to examine the fit to a normal distribution of the continuous variables. Participants' characteristics were described as means (standard deviations) (SDs) or percentages because of the normal distribution. Mean differences between genders were compared using Student's t-test, and relationships between categorical variables were tested using the chisquare test.

ANCOVA models were used to assess differences in overall satisfaction across the categories of supervision factors (meeting frequency with nurse teacher, good learning environment, satisfaction with supervisor, occurrence of supervision, role model of nursing professionals), duration of the placement and participants' characteristics, controlling for age and gender. Pairwise post hoc comparisons were performed using the Bonferroni correction for multiple comparisons. The duration of the placement was categorized as short (2-6 weeks) or long (7 weeks or more).

The good learning environment variable refers to the question about learning on the ward: 'The ward can be regarded as a good 
learning environment'. The satisfaction with supervision variable also refers to the question 'Overall, I am satisfied with the supervision I received'. Finally, the occurrence of supervision refers to a set of three alternatives proposed in Warne et al. (2010): (a) unsuccessful supervision experience, (b) group or team supervision, and (c) successful individualized supervision experience.

Simple mediation analysis models were run to examine whether the relationship between placement duration and overall satisfaction was mediated by the good learning environment and satisfaction with supervisor variables; the PROCESS macro for SPSS developed by Hayes (2013) (SPSS, Chicago, IL, USA) was used. Total (c) and direct effects $\left(a, b, c^{\prime}\right)$ were obtained, represented by the unstandardised regression coefficient and significant association between the independent and dependent variables in each model. With this model, we also obtained the indirect effect (IE) from the product of the coefficients $\left(a^{*} b\right)$, which indicates the change in overall satisfaction comparing short and long placement durations that is mediated by the proposed mediator (Hayes, 2013).

In addition, bootstrapping methods, as recommended by Preacher and Hayes (2008) were used to test the mediation hypotheses, using a resampling procedure of 10000 bootstrap samples. Point estimates and confidence intervals (95\%) were estimated for the IE. The point estimate was considered significant when the confidence interval did not contain zero. We also assessed mediation using the steps outlined by Sobel (1982). First, we estimated the attenuation or indirect effect, and we then divided the indirect effect by its standard error and performed a
$Z$ test of the null hypothesis that the indirect effect is equal to zero. The percentage of mediation (\%Med) was calculated (IE/c) to determine how much of the effect of placement duration on overall satisfaction operates indirectly through the proposed mediator.

A bilateral criterion for statistical significance of $p \leq 0.05$ was used. All statistical analyses were performed using IBM SPSS Statistics version 22 for Macintosh (SPSS, Inc., Chicago, IL).

\section{4 | RESULTS}

The characteristics of the sample are shown in Table 1. The mean placement duration was significantly longer among male students (mean 6.51 [SD 2.9] weeks) than among female students (mean 6.40 [SD 4.2]) ( $p=0.022)$. Only $13.5 \%$ of all participants $(N=1891)$ were dissatisfied with their clinical training, and there were no significant differences between the genders in terms of the mean total satisfaction score.

The differences in overall satisfaction across the categories of supervision factors (meeting frequency with nurse teacher, good learning environment, satisfaction with supervisor, occurrence of supervision, role model of nursing professionals), duration of the placement and student characteristics, controlling for age and gender, are presented in Table 2. Participants with longer placement durations were significantly more satisfied than their counterparts (mean 4.10 [SD 0.95] vs mean 3.97 [SD 1.02]; $p=0.010$ ). A noteworthy increase

\begin{tabular}{|c|c|c|c|c|}
\hline & Total & Male & Female & $p$-Value \\
\hline & 1891 & 210 & 1681 & \\
\hline Age, years (mean, SD) & $24.6(6.52)$ & $24.8(5.9)$ & $24.6(6.6)$ & 0.090 \\
\hline \multicolumn{5}{|l|}{ Education system, n (\%) } \\
\hline Polytechnic & $805(42.6)$ & $61(29.0)$ & $744(44.3)$ & $<0.001$ \\
\hline University college & $1086(57.4)$ & $149(71.0)$ & $937(55.7)$ & $<0.001$ \\
\hline \multicolumn{5}{|l|}{ Studying year, n (\%) } \\
\hline First & $197(10.5)$ & $23(11.2)$ & $174(10.4)$ & 0.788 \\
\hline Second & $858(45.4)$ & $123(59.7)$ & $735(43.9)$ & $<0.001$ \\
\hline Third or Fourth & $827(43.6)$ & $60(29.1)$ & $767(45.8)$ & $<0.001$ \\
\hline \multicolumn{5}{|l|}{ Geographical areas, n (\%) } \\
\hline Northern Europe & $652(34.4)$ & $55(26.2)$ & $597(35.5)$ & 0.007 \\
\hline Middle part of Europe & $642(34.1)$ & $43(20.5)$ & $599(35.6)$ & $<0.001$ \\
\hline Southern Europe & $597(31.5)$ & $112(53.3)$ & $485(28.9)$ & $<0.001$ \\
\hline Duration of the placement, weeks & $6.41(4.05)$ & $6.51(2.9)$ & $6.40(4.2)$ & 0.022 \\
\hline Total satisfaction (1-5), n (\%) & $4.01(1.00)$ & $3.96(1.0)$ & $4.00(1.0)$ & 0.835 \\
\hline Dissatisfied & $257(13.5)$ & 27 (12.9) & $230(13.7)$ & 0.742 \\
\hline Neither dissatisfied or satisfied & $846(44.6)$ & $100(47.6)$ & $746(44.4)$ & 0.373 \\
\hline Satisfied & 788 (41.9) & $83(39.5)$ & 705 (41.9) & 0.503 \\
\hline
\end{tabular}

TABLE 1 Characteristics of the study sample $(\mathrm{n}=1891)$

Note: Data are presented by mean (SD; standard deviation) or prevalence $\mathrm{n}$ (\%). $p$ Value refers to Student $t$-test analysis. Significant $p$ values are highlighted in bold. 
TAB LE 2 Mean differences of total satisfaction across categories of supervision factors, duration of the placement and student characteristics, controlling for age and gender

\begin{tabular}{|c|c|c|c|c|}
\hline & n & $\begin{array}{l}\text { Total satisfaction } \\
\text { mean (SD) }\end{array}$ & $p$-Value & Bonferroni \\
\hline \multicolumn{3}{|c|}{ Meeting frequency of nurse teacher during clinical training } & 0.128 & NS \\
\hline Not meetings & 243 & $4.04(1.12)$ & & \\
\hline $1-2$ times & 658 & $3.97(0.96)$ & & \\
\hline 3 times & 406 & $3.94(1.06)$ & & \\
\hline$>3$ times & 561 & $4.06(0.93)$ & & \\
\hline \multicolumn{3}{|l|}{ Duration of the placement } & 0.010 & - \\
\hline Short (2-6 weeks) & 1307 & $3.97(1.02)$ & & \\
\hline Long (7 weeks or more) & 574 & $4.10(0.95)$ & & \\
\hline \multicolumn{3}{|l|}{ Studying year } & 0.257 & NS \\
\hline First year & 196 & $4.01(1.04)$ & & \\
\hline Second year & 851 & $3.96(1.01)$ & & \\
\hline Third or Fourth year & 824 & $4.05(0.97)$ & & \\
\hline \multicolumn{3}{|l|}{ Good learning environment } & $<0.001$ & $1<2<3<4<5$ \\
\hline 1: Fully disagree & 86 & $1.72(0.67)$ & & \\
\hline 2: Disagree to some extent & 135 & $2.44(0.63)$ & & \\
\hline 3: Neither agree nor disagree & 207 & $3.22(0.64)$ & & \\
\hline 4: Agree to some extent & 555 & $3.95(0.55)$ & & \\
\hline 5: Fully agree & 878 & $4.68(0.48)$ & & \\
\hline \multicolumn{3}{|l|}{ Satisfaction with supervision } & $<0.001$ & $1<2<3<4<5$ \\
\hline 1: Fully disagree & 118 & $1.92(0.77)$ & & \\
\hline 2: Disagree to some extent & 166 & $2.60(0.67)$ & & \\
\hline 3: Neither agree nor disagree & 245 & $3.39(0.52)$ & & \\
\hline 4: Agree to some extent & 549 & $4.10(0.50)$ & & \\
\hline 5: Fully agree & 778 & $4.74(0.43)$ & & \\
\hline \multicolumn{3}{|l|}{ Occurrence of supervision } & $<0.001$ & NS between Group of team \\
\hline Unsuccessful experience & 274 & $3.04(1.15)$ & & supervision and "other" group \\
\hline Group or team supervision & 460 & $3.83(0.99)$ & & \\
\hline Successful individualized supervision relationship & 1060 & $4.34(0.74)$ & & \\
\hline Other & 48 & $3.72(1.07)$ & & \\
\hline \multicolumn{3}{|l|}{ Education system } & 0.046 & - \\
\hline Polytechnic & 799 & $3.94(1.03)$ & & \\
\hline University college & 1057 & $4.05(0.97)$ & & \\
\hline \multicolumn{3}{|l|}{ Role model of professional nursing } & $<0.001$ & NS between supervisor and NT \\
\hline Supervisor most important & 1105 & $4.15(0.89)$ & & equal and supervisor most important \\
\hline Supervisor and NT equal & 495 & $4.06(0.95)$ & & \\
\hline NT most important & 253 & $3.23(1.16)$ & & \\
\hline \multicolumn{3}{|l|}{ Geographical areas } & 0.007 & NS between Southern with Northern \\
\hline Northern Europe & 645 & $4.06(1.01)$ & & \\
\hline Middle part of Europe & 624 & $3.91(1.05)$ & & \\
\hline Southern Europe & 587 & $4.04(0.92)$ & & \\
\hline
\end{tabular}

Abbreviations: NS, Non-significant; NT, Nurse teacher. Notes: Significant $p$ values are highlighted in bold.

in overall satisfaction was found as participants' rating of the learning environment increased and as their satisfaction with their supervisor improved (both $p<0.001$ ).
Participants studying at university colleges were slightly but significantly more satisfied than those attending a polytechnic (4.05 [0.97] vs 3.94 [1.03]; $p=0.046)$. Finally, participants who considered 
(a)

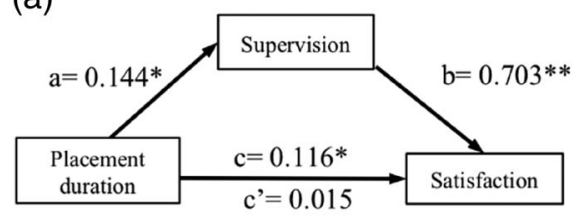

$\mathrm{IE}=0.101[0.016 ; 0.183]$

Sobel Test: $\mathrm{z}=\mathbf{2 . 3 0} \mathrm{p}=\mathbf{0 . 0 2 1}$

\%Med: $87.5 \%$ (b)

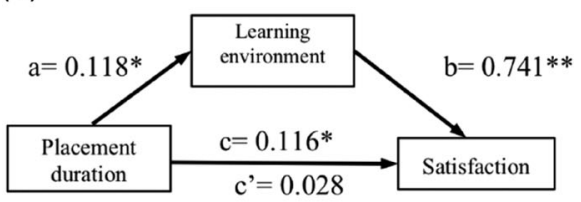

IE $=0.088[0.003 ; 0.170]$

Sobel Test: $\mathrm{z}=\mathbf{2 . 0 3} \mathrm{p}=\mathbf{0 . 0 4 3}$

\%Med: $\mathbf{7 5 . 7 \%}$

FIGURE 1 Mediation models of the relationship between placement duration and total satisfaction, controlling for age, gender, country, education system and year of study. Abbreviation: IE: Indirect effect. a, b, c and c' are expressed as the unstandardized regression coefficient, as suggested by Hayes (2013). ${ }^{*} p<0.05 ;{ }^{* *} p<0.001$. Placement duration is dichotomized as short (2-6 weeks), or long (7 weeks or more) duration. Supervision refers to satisfaction with supervisor; Learning environment refers to good learning environment perception

the supervisor the most important person in helping them understand the core concepts and practice of nursing were significantly more satisfied than those who considered the nurse teacher the most important (mean 4.15 [SD 0.89] vs mean 3.23 [SD 1.16]; $p=0.001$ ).

The mediation analysis including satisfaction with the supervisor as the mediator is shown in Figure 1a. Participants with longer placement durations were more satisfied with their supervisors than those involved in shorter placements $(a=0.144 ; p=0.021)$, and satisfaction with the supervisor was positively associated with total perceived satisfaction $(b=0.703 ; p<0.001)$. The mediation effect was confirmed by the Sobel test $(z=2.30 ; p=0.021)$ and the IE $(0.101$ [95\% Cl 0.016; 0.183]), which indicated that, those who undertook a placement of 7 weeks or more were 0.101 times more satisfied with their clinical training as a result of their satisfaction with their supervisor. Finally, the mediated percentage of satisfaction with the supervision in the relationship between placement duration and overall satisfaction was $87.5 \%$.

When the good learning environment factor was the proposed mediator (Figure 1b), the results followed the same path as previously described; participants with 7 weeks or more of clinical training perceived a better learning environment and were more satisfied, but when the mediator was included in the analysis, the total effect ( $\left.c^{\prime}\right)$ became non-significant $(0.028 ; p=0.313)$. The mediation effect was confirmed by the Sobel test $(z=2.03 ; p=0.043)$, and the IE indicated that those participants with a long ( $\geq 7$ weeks) clinical training were significantly (0.088 times) more satisfied as a result of the perceived good learning environment than participants with a short (2-6 weeks) clinical training (IE 0.088 [95\% Cl 0.003; 0.170]). The percentage of mediation of the learning environment was $75.7 \%$.

When the mediation analyses were run on the role model of nursing professionals (supervisor or nurse teacher as the most important person in helping them understand the core concepts and practice of nursing), neither satisfaction with the supervisor nor learning environment acted as mediators (data not shown). Finally, when the sample was distributed among the occurrence of supervision categories (unsuccessful experience, group or team supervision, successful individualized supervision relationship or other), there was no mediation effect of the proposed mediators (satisfaction with supervisor or learning environment) (data not shown).

\section{5 | DISCUSSION}

The aim of this study was to examine whether the relationship between the clinical placement duration and students' overall satisfaction with clinical training was mediated by the supervisory relationship or learning environment. Overall, our results show that students were more satisfied with longer placements. Furthermore, participants who perceived a better relationship with the supervisor and a better learning environment and considered the supervisor the most important person who helped them were those who performed longer clinical rotations. Moreover, these participants were more satisfied than those involved in shorter placements in clinical settings. Satisfaction with supervision and a good learning environment mediated the relationship between placement duration and the overall satisfaction of nursing students.

The importance of providing a supportive clinical learning environment to enhance teaching and learning is vital. Our results show that the students with the greatest satisfaction with their clinical training were those who considered the supervisor to be the most important figure. A literature review has already shown that there is no universal key person who is solely responsible for nursing professionals and development in clinical settings (Lambert \& Glacken, 2005), and studies in other countries still point out that the assessment of different figures involved in the learning process as reported by nursing students remains controversial (Dimitriadou et al., 2015). A recent study highlighted that a permanent and named supervisor, the quality of the student-supervisor relationship, the supervisor's involvement in the student's learning process and the supervisor's support of the student's professional development increase the student's satisfaction with the clinical learning environment (Saukkoriipi et al., 2020). The further developed T-subscale of the CLES+T (Strandell-Laine et al., 2018) can partly solve and clarify the nurse teacher's pedagogical cooperation with students during their clinical training.

Nonetheless, the diversity of the terms used across Europe to describe those responsible for students' supervision should be highlighted (Andrews et al., 2006; Ramage, 2004). Additionally, the implementation of higher education has transformed the role of nurse 
teachers, who have become more responsible for the support of learners in practice placements (Fisher, 2005), and self-learning has become an essential issue within this new learning context (Alotaibi, 2016). Dev et al. (2020) pointed out that the presence of a nurse teacher in clinical settings and avoidance of hierarchical communication between supervisors and nurse teachers could enhance clinical education. Saukkoriipi et al. (2020) highlighted the importance of the supervisors and nurse teachers performing the final nursing student assessments jointly.

To date, several studies have reported that the supervision provided by nurses, the level of cooperation with the nurse teacher and the relationship among the student, supervisor and nurse teacher are the most important extrinsic factors influencing the clinical learning experiences of students (Papastavrou et al., 2016; Saarikoski et al., 2009; Warne et al., 2010). Moreover, a good perception of the clinical learning environment and supervision increases the intention to stay and consider the placement hospital as a future workplace (Rodríguez-García et al., 2021). In accordance with Antohe et al. (2016) and Saukkoriipi et al. (2020), our results confirm that the participants were more satisfied with their clinical training when they spent more time in that placement. To our knowledge, the duration of clinical placements varies from 1 week in Slovenia (Žvanut et al., 2018) to an entire academic year in England and Scotland (McCallum et al., 2016; Roxburgh et al., 2012). In those cases where the clinical placement was short, a lack of familiarity between the staff and the students (Dimitriadou et al., 2015; Žvanut et al., 2018) and the lack of opportunities to develop relationships with patients (Al-Anazi et al., 2019) were considered the main drawbacks. In those cases where the clinical placement was the same throughout the academic year, the hub and spoke model of practice was implemented. The hub model consists of a non-rotational organization of clinical learning in which the students return to the same placement on three separate occasions throughout the academic year for placement blocks; the hub placement therefore helps to promote and enhance belongingness for the student and continuity of mentorship and assessment. The spoke model consists of a secondary care area linked closely to the hub, reflecting the patient journey across healthcare settings. Hub placements appear to be a good way to increase the duration of clinical training and stimulate interaction with supervisors (McCallum et al., 2016; Thomas \& Westwood, 2016); when students return periodically to the same ward at different times during their nursing degree programme, their satisfaction with their clinical training increases. One of the explanations could be that the nursing team was previously trained and therefore more experienced. Nevertheless, returning periodically to the same ward is not equivalent to increasing the duration of the placement. Similarly, Hutchings et al. (2005) suggest that performing the same week shift pattern as the nursing staff creates opportunities for students to take advantage of learning opportunities and become familiar with the staff, thereby developing rapport within the nursing team (Bradshaw et al., 2018).

Several factors have been highlighted as necessary for a good learning environment. These include the pedagogical atmosphere on the ward and the establishment of supportive interpersonal communication with supervisors (Baraz et al., 2015; Rodríguez-García et al., 2021). In relation to these factors, the literature states that students refer to two core elements related to the pedagogical framework: envisioning the self as incompetent (Beck, 1993) and the feeling of being an outsider, i.e., not feeling included as part of the working team (Chan, 2001; Melia, 1987). According to Christiansen and Bell (2010), peer learning is a good tool to minimize these two effects in pre-registration nursing students. The reciprocity of peer learning partnerships facilitates understanding of mentorship, creates a heightened sense of readiness for professional practice, and helps more experienced students gain confidence. Other factors related to the higher education of clinical training and that have been highlighted for their influence on the learning environment are preference in the choice of the clinical training placement, students' high mean score, hospital and public management (Fernández-García et al., 2020), a small number of students supervised by the clinical educators (Fernández-García et al., 2021), and mentorship continuity (Lee \& Chiang, 2021). Thus, adequate organization of clinical training is a key element for improving learning outcomes and the satisfaction of nursing students (Bisholt et al., 2014; Payne, 2016).

Finally, it has been stated that intrinsic motivation and anxiety need to be controlled because they affect academic achievement (Khalaila, 2015). Our results show that a good learning environment mediates the relationship between the duration of the placement and overall satisfaction with clinical training. Ip and Chan (2005) also found student involvement and personalization to be significant predictors of satisfaction. Nonetheless, neither of these variables were included in the CLES+T scale. Therefore, further research on the predictors of student satisfaction in clinical settings that clarifies the extent to which these variables depend on the duration of placement is needed to increase generalizability.

\subsection{Limitations}

Our study has several limitations that should be acknowledged. First, the secondary analyses are constrained by the parameters of the primary data they are reanalysing and are thus affected by lack of control over sampling techniques and the possibility of data entry and coding errors. Second, even though the CLES $+\mathrm{T}$ scale was originally designed to measure the level of satisfaction of nursing students with the clinical learning environment and supervision in hospital settings (Saarikoski \& Leino-Kilpi, 2002), its validation in community settings in Sweden (Bos et al., 2012) and New Zealand (Sims et al., 2010) proved its applicability in primary care practice settings. Nonetheless, as Bos et al. (2012) highlighted, nursing students' satisfaction could be increased in primary care practice settings by different factors, such as one-on-one supervision and the opportunity to care for patients in their homes and for a long period of time. Consequently, these results cannot be generalized to the primary care level. Therefore, an indepth analysis of the degree of satisfaction of students in nonhospital settings is necessary. Third, the cross-sectional design prevented us from making cause and effect inferences. Finally, 
complex models, the inclusion of more than one mediator, moderation-mediation models or longitudinal data would be useful in future research to confirm our findings.

\section{6 | CONCLUSIONS}

The research findings of this study indicated that the relationship between the duration of placement and overall satisfaction are mediated by both satisfaction with the supervisor and how good the learning environment is perceived to be. Despite this, establishing the optimal duration of clinical training to achieve a balance between producing fully competent nurses and attaining the maximum level of satisfaction in the practicum ward requires further investigation and in-depth consideration. Nevertheless, and taking into account the available evidence in this field, it seems feasible that a duration of approximately 7 weeks could be the starting point to design future research in this field. The variability in nursing degree studies among European countries is high, and although efforts have been made to achieve homogeneous curricula, joint effort is necessary to obtain a homogeneous placement duration across Europe to standardize nursing education according to Europe-wide policies.

The role of nurse teachers, supervisors, ward managers and staff in contributing to the acquisition of competences by nursing students needs to be clarified. The movement of hospital-based education into higher education has transformed the clinical learning process; hence, more recruitment of capable nurse teachers and supervisors is needed, and assess their educational performance and clinical skills. It is also necessary to establish standards and validate education quality. Exploring the division of labour and enhancing educators' skills may be important strategies in the pursuit of an evidence based for nursing practice in clinical situations.

\section{7 | RELEVANCE FOR CLINICAL PRACTICE}

It is imperative that higher educational institutions and health care centres work together to define the roles of nurse teachers, supervisors and ward managers in contributing to the acquisition of competences by nursing students. Despite the creation of the EHEA and the existence of European directives for pre-registration nursing education programs, it is clear that clarification of the duration and design of practical training across Europe is mandatory. As a first approximation based on the evidence obtained, it seems feasible that a duration of approximately 7 weeks could be the starting point to design future research in this field.

\section{ACKNOWLEDGMENTS}

We thank Mikko Saarikoski, Tony Warne, Unn-Britt Johansson, Evridiki Papastavrou, Erna Tichelaar, Marco Tomietto, Koen van den Bossche, and María Flores Vizcaya-Moreno for the permission of using the data. We thank the schools and students their enthusiastic participation in the study.

\section{AUTHOR CONTRIBUTIONS}

Study design: Alberto González-García, Ana Díez-Fernández, Helena Leino-Kilpi, and Camilla Strandell-Laine. Data collection: Helena Leino-Kilpi and Camilla Strandell-Laine. Data analysis: Alberto González-García and Ana Díez-Fernández. Manuscript writing: Alberto González-García, Ana Díez-Fernández, Helena Leino-Kilpi, Vicente Martínez-Vizcaíno, and Camilla Strandell-Laine.

\section{DATA AVAILABILITY STATEMENT}

The data that support the findings of this study are available from the corresponding author upon reasonable request.

\section{ORCID}

Alberto González-García (D) https://orcid.org/0000-0001-7314-1435

Ana Díez-Fernández (D) https://orcid.org/0000-0002-7673-986X

Helena Leino-Kilpi (D) https://orcid.org/0000-0003-2477-971X

Vicente Martínez-Vizcaíno (D) https://orcid.org/0000-0001-6121-7893

Camilla Strandell-Laine (ID https://orcid.org/0000-0002-8023-1428

\section{REFERENCES}

Al-Anazi, N. A., Alosaimi, D., Pandaan, I., Anthony, D., \& Dyson, S. (2019). Evaluating clinical placements in Saudi Arabia with the CLES+T scale. Nurse Education in Practice, 39(May), 11-16.

All European Academies -ALLEA. (2017). The European code of conduct for research integrity (Revised ed.). ALLEA. https://doi.org/10.1037/ e648332011-002

Alotaibi, K. N. (2016). The learning environment as a mediating variable between self-directed learning readiness and academic performance of a sample of saudi nursing and medical emergency students. Nurse Education Today, 36, 249-254.

Andrews, G. J., Brodie, D. A., Andrews, J. P., Hillan, E., Gail Thomas, B., Wong, J., \& Rixon, L. (2006). Professional roles and communications in clinical placements: A qualitative study of nursing students' perceptions and some models for practice. International Journal of Nursing Studies, 43(7), 861-874.

Antohe, I., Riklikiene, O., Tichelaar, E., \& Saarikoski, M. (2016). Clinical education and training of student nurses in four moderately new European Union countries: Assessment of students' satisfaction with the learning environment. Nurse Education in Practice, 17, 139-144.

Atay, S, Kurt, FY, Aslan, GK, Saarikoski, M, Yılmaz, H, \& Ekinci, V (2018). Validity and reliability of the Clinical Learning Environment, Supervision and Nurse Teacher (CLES + T), Turkish version1. Rev Lat Am Enfermagem, 26, e3037. https://doi.org/10.1590/1518-8345.2413.3037.

Baraz, S., Memarian, R., \& Vanaki, Z. (2015). Learning challenges of nursing students in clinical environments: A qualitative study in Iran. Journal of Education and Health Promotion, 4(1), 52.

Beck, C. (1993). Nursing students initial clinical experience: A phenomenological study. International Journal of Nursing Studies, 30, 489-497.

Bisholt, B., Ohlsson, U., Engström, A. K., Johansson, A. S., \& Gustafsson, M. (2014). Nursing students' assessment of the learning environment in different clinical settings. Nurse Education in Practice, 14(3), 304-310.

Bos, E., Alinaghizadeh, H., Saarikoski, M., \& Kaila, P. (2012). Validating the "clinical learning environment, supervision and nurse teacher" CLES $+\mathrm{T}$ instrument in primary healthcare settings using confirmatory factor analysis. Journal of Clinical Nursing, 21(11-12), 17851788.

Bradshaw, C., Murphy Tighe, S., \& Doody, O. (2018). Midwifery students' experiences of their clinical internship: A qualitative descriptive study. Nurse Education Today, 68, 213-217. 
Chan, D. S. K. (2001). Combining qualitative and quantitative methods in assessing hospital learning environments. International Journal of Nursing Studies, 38(4), 447-459.

Christiansen, A., \& Bell, A. (2010). Peer learning partnerships: Exploring the experience of pre-registration nursing students. Journal of Clinical Nursing, 19(5-6), 803-810.

Dev, MDB, Rusli, KDB, McKenna, L, Lau, ST, \& Liaw, SY (2020). Academicpractice collaboration in clinical education: A qualitative study of academic educator and clinical preceptor views. Nurs Health Sci, 22(4), 1131-1138. https://doi.org/10.1111/nhs.12782

Dimitriadou, M., Papastavrou, E., Efstathiou, G., \& Theodorou, M. (2015). Baccalaureate nursing students' perceptions of learning and supervision in the clinical environment. Nursing and Health Sciences, 17(2), 236-242.

Education Audiovisual and Culture Executive Agency (EAECEA P9 Eurydice). (2009). Higher education in Europe 2009: Developments in the Bologna process. Education, Audiovisual and Culture Executive Agengy (EACEA P9 Eurydice). https://doi.org/10.2797/14010

European Commission. (2005). Directive 2005/36/EC on the recognition of professional qualifications. Official Journal of the European Union, 255, 22-142.

European Commission. (2013). Directive 2013/55/EU of the European Parliament and of the council. Official Journal of the European Union 354, 132-170 http://eur-lex.europa.eu/LexUriServ/LexUriServ.do? uri=OJ:L:2013:354:0132:0170:en:PDF

European Commission. (2020). Forces shaping and challenging the resilience of the health workforce. https://ec.europa.eu/\%0Ahealth/ workforce/overview_en

Fernández-García, D, Giménez-Espert, MDC, Castellano-Rioja, E, \& PradoGascó, V. (2020). What Academic Factors Influence Satisfaction With Clinical Practice in Nursing Students? Regressions vs. fsQCA. Front Psychol, 11, 585826. https://doi.org/10.3389/fpsyg.2020.585826

Fernández-García, D, Moreno-Latorre, E, Giménez-Espert, MdC, \& PradoGascó, V (2021). Satisfaction with the clinical practice among nursing students using regression models and qualitative comparative analysis. Nurse Educ Today, 100, 104861. https://doi.org/10.1016/j.nedt.2021. 104861

Fisher, M. T. (2005). Exploring how nurse lecturers maintain clinical credibility. Nurse Education in Practice, 5(1), 21-29.

Flinkman, M., Leino-Kilpi, H., Numminen, O., Jeon, Y., Kuokkanen, L., \& Meretoja, R. (2017). Nurse competence scale: A systematic and psychometric review. Journal of Advanced Nursing, 73(5), 1035-1050.

Hayes, A. F. (2013). Introduction to mediation, moderation, and conditional process analysis: A regression-based approach (2nd ed.). Guilford Press.

Heaton, J. (2004). Reworking qualitative data. Sage Publications.

Hutchings, A., Williamson, G. R., \& Humphreys, A. (2005). Supporting learners in clinical practice: Capacity issues. Journal of Clinical Nursing, 14(8 A), 945-955.

Ip, W. Y., \& Chan, D. S. K. (2005). Hong Kong nursing students' perception of the clinical environment: A questionnaire survey. International Journal of Nursing Studies, 42(6), 665-672.

Jack, K., Hamshire, C., Harris, W. E., Langan, M., Barrett, N., \& Wibberley, C. (2018). "My mentor didn't speak to me for the first four weeks": Perceived unfairness experienced by nursing students in clinical practice settings. Journal of Clinical Nursing, 27(5-6), 929-938.

Jacobson, A. F., Hamilton, P., \& Galloway, J. (1993). Obtaining and evaluating data sets for secondary analysis in nursing research. Western Journal of Nursing Research, 15(4), 483-494.

Kajander-Unkuri, S., Koskinen, S., Brugnolli, A., Cerezuela Torre, M., Elonen, I., Kiele, V., Lehwaldt, D., Löyttyniemi, E., Nemcová, J., de Oliveira, C. S., Palese, A., Rua, M., Salminen, L., Šateková, L., Stubner, J., Sveinsdóttir, H., Visiers-Jiménez, L., \& Leino-Kilpi, H. (2020). The level of competence of graduating nursing students in 10 European countries-Comparison between countries. Nursing Open, 8, 1048-1062. https://doi.org/10.1002/nop2.712
Kajander-Unkuri, S., Salminen, L., Saarikoski, M., Suhonen, R., \& LeinoKilpi, H. (2013). Competence areas of nursing students in Europe. Nurse Education Today, 33(6), 625-632.

Khalaila, R. (2015). The relationship between academic self-concept, intrinsic motivation, test anxiety, and academic achievement among nursing students: Mediating and moderating effects. Nurse Education Today, 35(3), 432-438.

Lahtinen, P., Leino-Kilpi, H., \& Salminen, L. (2014). Nursing education in the European higher education area: Variations in implementation. Nurse Education Today, 34(6), 1040-1047.

Lambert, V., \& Glacken, M. (2005). Clinical education facilitators: A literature review. Journal of Clinical Nursing, 14(6), 664-673.

Laude, W., Watson, R., Topping, K., Holland, K., Johnson, M., Porter, M., Roxburg, M., \& Behr, A.(2008). An evaluation of fitness for practice curricula: self-efficacy, support and self-reported competence in preregistration student nurses and midwives. $J$ Clin Nurs, 17(14), 1858-1867. https://doi.org/10.1111/j.1365-2702.2007. 02223.

Lee, N. P. M., \& Chiang, V. C. L. (2021). The mentorship experience of students and nurses in pre-registration nursing education: A thematic synthesis of qualitative studies. Nursing and Health Sciences, 23(1), 69-86.

Manninen, K, Henriksson, EW, Scheja, M, \& Silén, C. (2015). Supervisors' pedagogical role at a clinical education ward - an ethnographic study. BMC Nurs, 14, 55. https://doi.org/10.1111/10.1186/s12912-0150106-6.

McCallum, J., Lamont, D., \& Kerr, E. L. (2016). First year undergraduate nursing students and nursing mentors: An evaluation of their experience of specialist areas as their hub practice learning environment. Nurse Education in Practice, 16(1), 182-187.

Melia, K. M. (1987). Learning and working: The occupational socialization of nurses. International Journal of Health Planning and Management. London: Tavistock.

Milner, F. M., Estabrooks, C. A., \& Humphrey, C. (2005). Clinical nurse educators as agents for change: Increasing research utilization. International Journal of Nursing Studies, 42(8), 899-914.

Morphet, J., Hood, K., Cant, R., Baulch, J., Gilbee, A., \& Sandry, K. (2014). Teaching teamwork: An evaluation of an interprofessional training ward placement for health care students. Advances in Medical Education and Practice, 5, 197-204.

Papastavrou, E., Dimitriadou, M., Tsangari, H., \& Andreou, C. (2016). Nursing students' satisfaction of the clinical learning environment: $A$ research study. BMC Nursing, 15(1), 1-10.

Payne, C. (2016). Transitions into practice: First patient care experiences of baccalaureate nursing students. Nurse Education in Practice, 16(1), 251-257.

Pitkänen, S., Kääriäinen, M., Oikarainen, A., Tuomikoski, A.-M., Elo, S., Ruotsalainen, H., Saarikoski, M., Kärsämänoja, T., \& Mikkonen, K. (2018). Healthcare students' evaluation of the clinical learning environment and supervision: A cross-sectional study. Nurse Education Today, 62, 143-149.

Preacher, K., \& Hayes, A. F. (2008). Asymptotic and resampling strategies for assessing and comparing indirect effects in multiple mediator models. Behavior Research Methods, 40(3), 879-891.

Ramage, C. (2004). Negotiating multiple roles: Link teachers in clinical nursing practice. Journal of Advanced Nursing, 45(3), 287-296.

Rodríguez-García, M. C., Gutiérrez-Puertas, L., Granados-Gámez, G., Aguilera-Manrique, G., \& Márquez-Hernández, V. V. (2021). The connection of the clinical learning environment and supervision of nursing students with student satisfaction and future intention to work in clinical placement hospitals. Journal of Clinical Nursing, jocn.15642. 30, 986-994. https://doi.org/10.1111/jocn.15642

Roxburgh, M., Conlon, M., \& Banks, D. (2012). Evaluating hub and spoke models of practice learning in Scotland, UK: A multiple case study approach. Nurse Education Today, 32(7), 782-789. 
Saarikoski, M., Isoaho, H., Warne, T., \& Leino-Kilpi, H. (2008). The nurse teacher in clinical practice: Developing the new sub-dimension to the clinical learning environment and supervision (CLES) scale. International Journal of Nursing Studies, 45(8), 1233-1237.

Saarikoski, M., Kaila, P., Lambrinou, E., Pérez Cañaveras, R. M. Tichelaar, E., Tomietto, M., \& Warne, T. (2013). Students' experiences of cooperation with nurse teacher during their clinical placements: An empirical study in a Western European context. Nurse Education in Practice, 13(2), 78-82.

Saarikoski, M., \& Leino-Kilpi, H. (2002). The clinical learning environment and supervision by staff nurses: Developing the instrument. International Journal of Nursing Studies, 39(3), 259-267.

Saarikoski, M., Warne, T., Kaila, P., \& Leino-Kilpi, H. (2009). The role of the nurse teacher in clinical practice: An empirical study of Finnish student nurse experiences. Nurse Education Today, 29(6), 595-600.

Saukkoriipi, M., Tuomikoski, A. M., Sivonen, P., Kärsämänoja, T., Laitinen, A., Tähtinen, T., Kääriäinen, M., Kuivila, H. M., Juntunen, J., Tomietto, M., \& Mikkonen, K. (2020). Clustering clinical learning environment and mentoring perceptions of nursing and midwifery students: A cross-sectional study. Journal of Advanced Nursing, 76(9), 2336-2347

Sims, D., Watson, P., Seaton, P., Whittle, R., Jamieson, I., Saarikoski, M., \& Mountier, J. (2010). Evaluating the quality of workplace learning for nursing students in community settings. Ako Aotearoa, 1-3. https:// ako.ac.nz/knowledge-centre/evaluating-the-quality-of-workplacelearning-for-nursing-students-in-community-settings/.

Sobel, M. E. (1982). Asymptotic confidence intervals for indirect effects in structural equation models. Sociological Methodology, 13, 290-312.

Strandell-Laine, C., Saarikoski, M., Löyttyniemi, E., Meretoja, R., Salminen, L., \& Leino-Kilpi, H. (2018). Effectiveness of mobile cooperation intervention on students' clinical learning outcomes: A randomized controlled trial. Journal of Advanced Nursing, 74(6), 1319-1331.
Thomas, M., \& Westwood, N. (2016). Student experience of hub and spoke model of placement allocation: An evaluative study. Nurse Education Today, 46, 24-28.

Tomietto, M., Comparcini, D., Simonetti, V., Pelusi, G., Troiani, S., Saarikoski, M., \& Cicolini, G. (2016). Work-engaged nurses for a better clinical learning environment: A ward-level analysis. Journal of Nursing Management, 24(4), 475-482.

Visiers-Jiménez, L, Suikkala, A, Salminen, L, Leino-Kilpi, H, Löyttyniemi, E, Henriques, MA, Jiménez-Herrera, M, Nemcová, J, Pedrotti, D, Rua, M, Tommasini, C, Zeleníková, R, \& Kajander-Unkuri, S. (2021). Clinical learning environment and graduating nursing students' competence: $A$ multi-country cross-sectional study. Nurs Health Sci, 1-13. https://doi. org/10.1111/nhs.12819

Warne, T., Johansson, U. B., Papastavrou, E., Tichelaar, E., Tomietto, M., Van den Bossche, K., Moreno, M. F. V., \& Saarikoski, M. (2010). An exploration of the clinical learning experience of nursing students in nine European countries. Nurse Education Today, 30(8), 809-815.

Žvanut, B., Lovrić, R., Kolnik, T. Š., Šavle, M., \& Pucer, P. (2018). A Slovenian version of the "clinical learning environment, supervision and nurse teacher scale (Cles+T)" and its comparison with the Croatian version. Nurse Education in Practice, 30(March 2017), 27-34.

How to cite this article: González-García, A., Díez-Fernández, A., Leino-Kilpi, H., Martínez-Vizcaíno, V., \& Strandell-Laine, C. (2021). The relationship between clinical placement duration and students' satisfaction with the quality of supervision and learning environment: A mediation analysis. Nursing \& Health Sciences, 1-10. https://doi.org/10.1111/nhs.12855 